https://www.journal-imab-bg.org

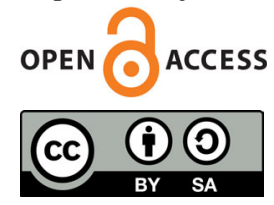

Case report

\title{
TRANSCATHETER AORTIC VALVE IMPLANTATION IN A PATIENT WITH PROSTHETIC MITRAL VALVE- CLINICAL CASE
}

\author{
Veselin Valkov $^{1}$, Dobrin Kalchev ${ }^{1}$, Atanas Kostadinov ${ }^{1}$, Yavor Kashlov², Branimir \\ Kanazirev $^{2}$ \\ 1) Medical University, Varna, Bulgaria, Faculty of Medicine, First Clinic of \\ Cardiology, UMHAT “St. Marina”, Varna, \\ 2) Department of Internal Medicine, UMHAT “St. Marina”, Faculty of Medicine, \\ Medical University, Varna, Bulgaria.
}

\begin{abstract}
:
TAVI is a relatively new interventional procedure designed for management of aortic stenosis in patients with high surgical risk. Performing it on someone with a prosthetic mitral valve is a challenge, made much easier by the new delivery systems and valves. We present one such procedure and try to put some light on the difficulties that await along the way to successful implantation.
\end{abstract}

Keywords: Transcatheter aortic-valve implantation (TAVI), aortic artery stenosis, prosthetic mitral valve

\section{INTRODUCTION:}

We are presenting a case of TAVI procedure in a patient with a prosthetic mitral valve. TAVI is possibly the only reasonable option for aortic valve replacement in patients with previous cardiac surgery, severe comorbidity and as a consequence - high surgical risk. The TAVI procedure becomes challenging in patients with prosthetic mitral valves because of a possible confrontation of the two valves.

The treatment of aortic stenosis has changed dramatically since Alain Cribier performed the first TAVI in the year 2002. The development of the devices required for this procedure is still undergoing [1]. The first TAVI patient overcame the cardiogenic shock in which he was before the procedure but still died a few months after due to severe comorbidity. Despite this result, a rapid development of both valves and delivery systems followed. In Europe in 2007 two entirely different valves were approved for use - Sapien, produced by Edwards Life sciences and CoreValve, made by Medtronic. The first one is a balloon -expandable valve with the possibility for transfemoral, transaortic and transapical access and the second one is a nitinol-based, self-expandable, and requiring transfemoral and transaxial arterial access.

In contrast to the femoral vein access and transseptal antegrade approach that was used by Cribier and made the procedure even more difficult, the newly developed delivery systems and options for access site make the procedure simple for an experienced interventional cardiologist.
Today TAVI is not only and alternative but a default choice for patients with high surgical risk [2]. In the first randomised trial studying TAVI (called PARTNER), the presence of an artificial mitral valve was an exclusion criterion. The main reason for that is the possibility of dysfunction of the mitral leaflets when the aortic valve is expanded or even the occurrence of slippage - the "watermelon seed effect" $[3,4]$. There is also the danger of prosthesis embolization during or after aortic valve implantation due to the rigidity of the artificial mitral valve [5]. Despite the multiple challenges of such procedure, many authors share their experience and describe the procedure as entirely possible.

The literature review, performed by Katie E O'Sullivan et al. includes 397 publications related to TAVI in patients with an artificial mitral valve. It determines that the 30 -day survivability is almost $100 \%$, aside from the death of one female patient with severe comorbidity and LVEF of $10 \%$ [6]. Only two cases of valve embolization were reported. They were considered to be a consequence of undersizing, severe or asymmetrical calcification of the aortic root, ballooning of the basal segments of the septum, low implantation, too high implantation mainly due to mechanical valve prosthesis. This substantial literature review concludes that TAVI in a patient with previous MVR is not only possible but also advisable and not associated with any significant increase in the periprocedural risk.

\section{CLINICAL CASE DESCRIPTION:}

We present the clinical case of a female patient aged 71 years who have been treated at First Clinic of Cardiology at St. Mary's Hospital in Varna. She is known to suffer from a degenerative aortic stenosis. She received an artificial mitral valve (Medtronic Advantage Mechanical Heart Valve No28) because of a mitral regurgitation and a stenosis 10 years ago. For the last few months, she started to experience angina and heart failure symptoms. She also suffers from permanent atrial fibrillation, COPD, anemia and dyslipidemia.

She takes the following medication: Clopidogrel $75 \mathrm{mg}$ o.d., Acenocoumarol, Furosemide 40mg $2+2+0$, Spironolactone $25 \mathrm{mg}$ o.d., Nebivolol $5 \mathrm{mg}$ o.d., Atorvastatin 
20mg o.d. and Iron supplement.

The physical examination reveals systolic murmur 4/6 grade heard over the whole precordium, mitral valvular click, RR-110/70mmHg and HR- 80/min absolute arrhythmia.

The laboratory findings (Blood count, ALAT, ASAT, CK, CK-MB,Troponin, Total cholesterol, HDL, LDL, Creatinine, $\mathrm{Na}, \mathrm{K}, \mathrm{CL}$ ) are all within normal range.

The ECG shows absolute arrhythmia, HR 70/min and nonspecific intraventricular conduction delay.

We performed transthoracic echocardiogram which revealed $\mathrm{LVEF}=62 \%$, no wall motion abnormalities, dilated $\mathrm{LA}=79 \mathrm{~mm}$, a normal function of the mitral valve prosthesis, Aortic Vmax $=4.25 \mathrm{~m} / \mathrm{s}$ and $\mathrm{PG}=72.5 \mathrm{mmHg}$, Trivial tricuspid regurgitation and an absence of pericardial effusion.

In order to deem a patient at high risk for surgery certain risk scores must be calculated. In our patient they were as follows: EuroSCORE II $-8.03 \%$ (high risk when > $6 \%$ ), LogisticEuroSCORE $=12.39 \%$ (high risk when $>$ $20 \%$ ), STS score $=11.58 \%$ (high risk $>10 \%$ ). The VARC (Valve Academy Research Consortium) recommendations are designed specifically for the needs of interventional cardiology and TAVI [2].

After taking into consideration all of the above mentioned scores and the additional comorbidity of the patient the Heart Team (consisting of a cardiac surgeon, cardiologist, interventional cardiologist, anesthesiologist and rentgenologist) decided that another thoracotomy and cardioplegia bear the too high risk for her and recommended her a TAVI procedure.

As preparation for the upcoming TAVI procedure we did the following:

- Selective coronary angiography, revealing 90\% stenosis of proximal LAD and PCI of the lesion using Drugeluting Stent (DES) (Fig. 1.).

Fig. 1. Stenosis of LAD before and after PCI.

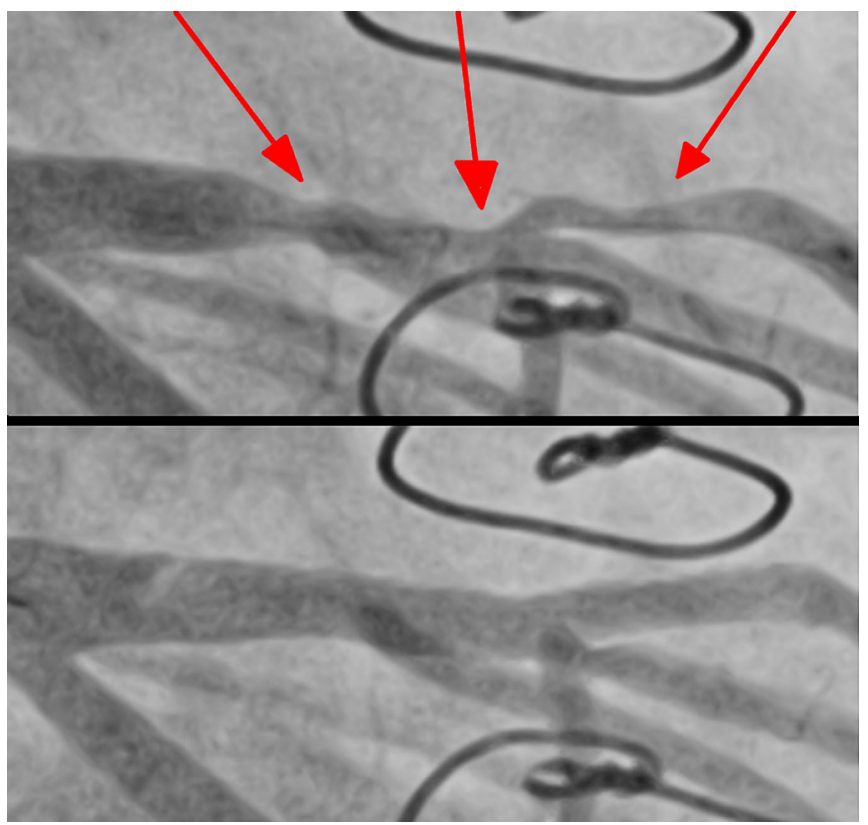

- Manometria (using the pull back method) showing $80 \mathrm{mmHg}$ peak gradient through the Aortic valve.

- Aorto-arteriographia in order to measure the aortic annulus $(20.5 \mathrm{~mm})$, sinuses of Valsalva $(26.5 \mathrm{~mm})$, STJ $(27.5 \mathrm{~mm})$, ascending aorta $(33 \mathrm{~mm})$ and the diameters of iliac and femoral arteries which met the minimum requirements of the delivery system.

- TEE that showed first degree MR and a nonsignificant PFO with a minimal left to right shunt (Fig. 2.).

Fig. 2. Transesophageal echo visualising aortic anulus and LVOT

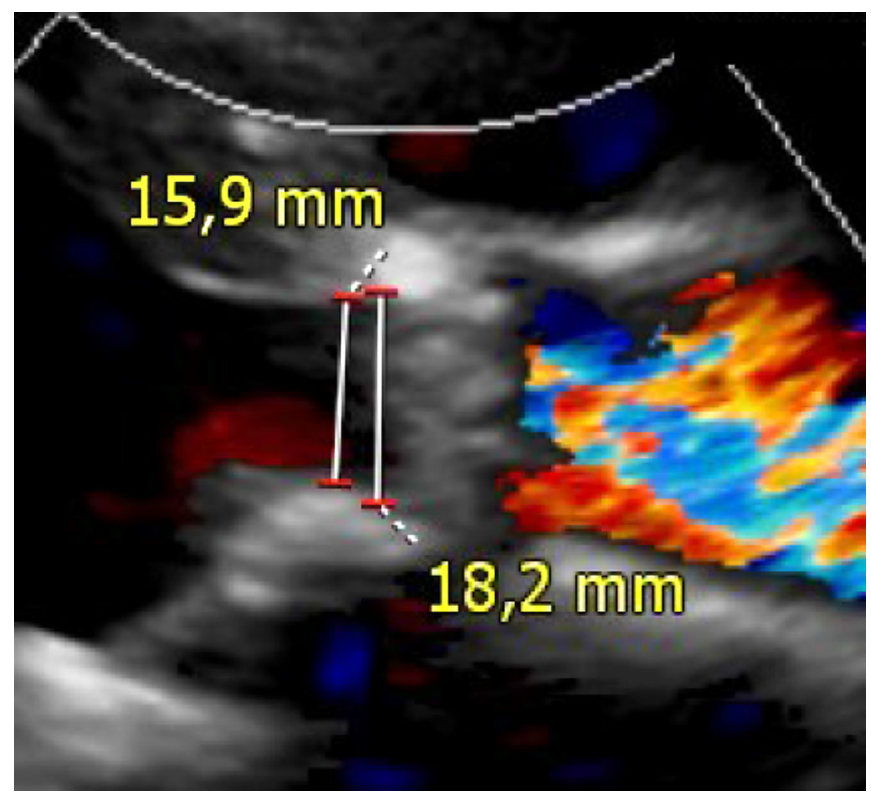

- Multi slice Computer Tomography (Fig. 3.) verified the diameter of the aorta at different levels Fig. 4. This imaging method was also used for the measurement of the distance between the aortic annulus and the upper border of the mitral valve. It was deemed enough for a safe TAVI procedure Fig. 5. 
Fig. 3. MSCT of LVOT and Aortic Root

ANNULUS

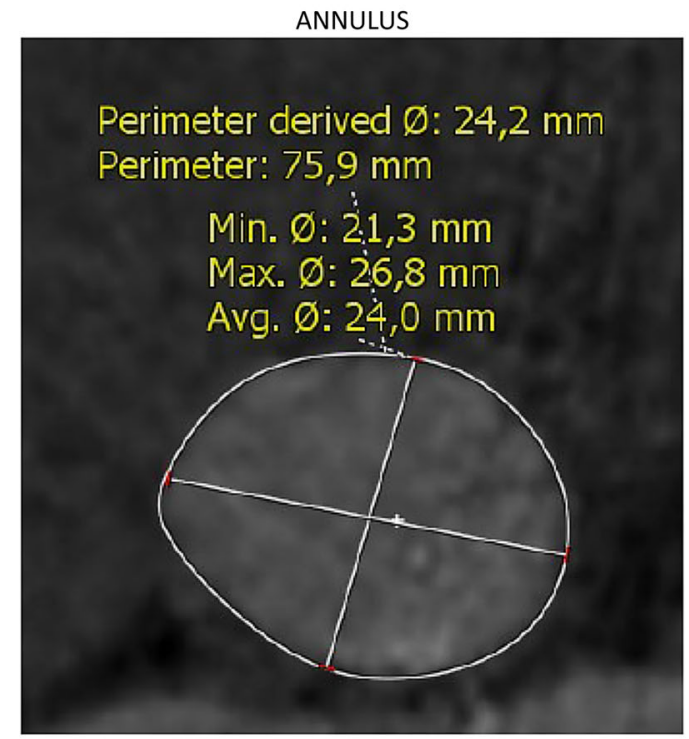

LVOT

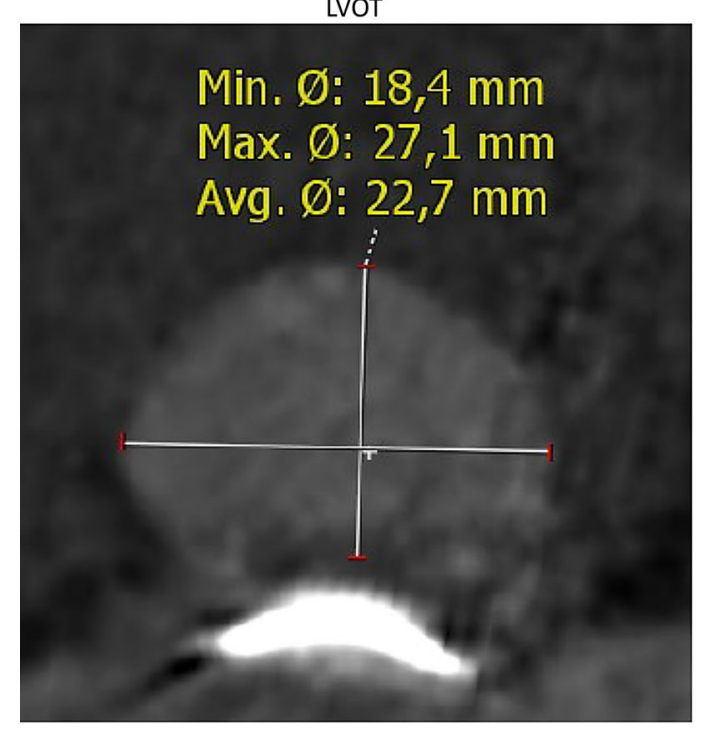

SOV DIAMETER

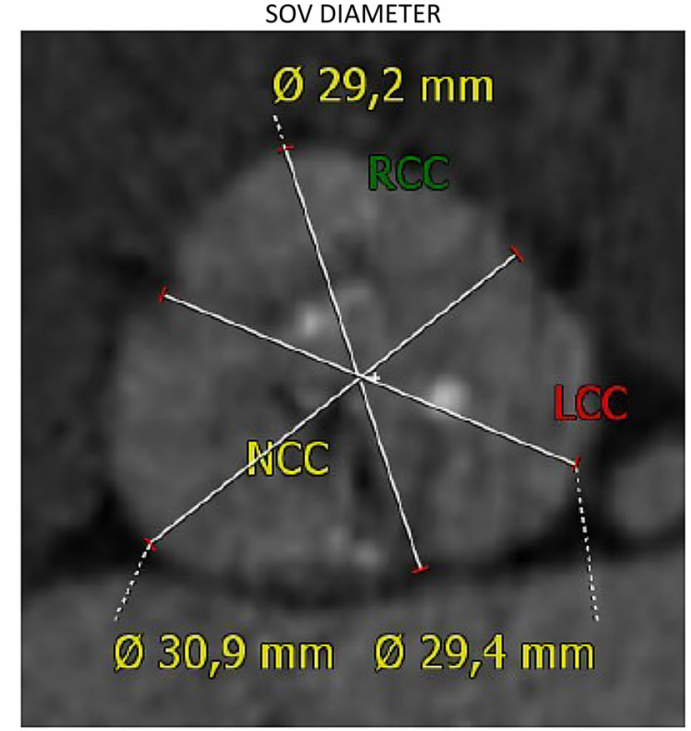

ASCENDING AORTA

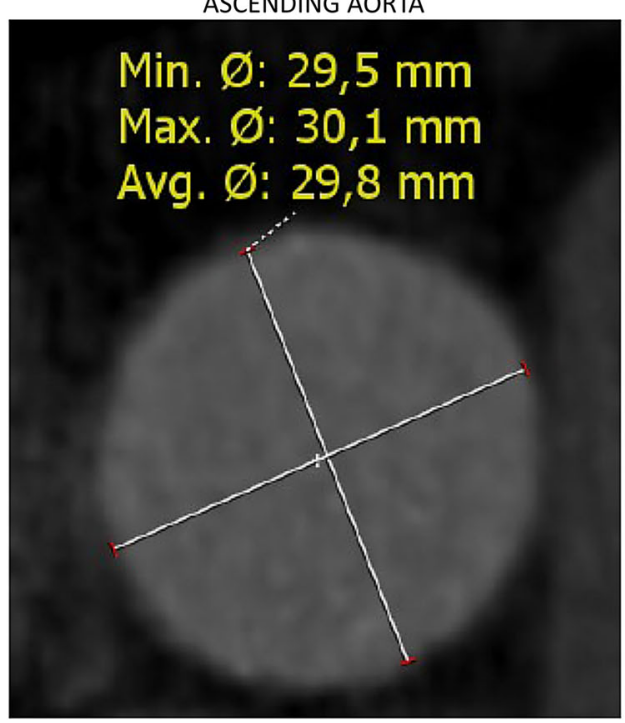

Fig. 4. 3D reconstruction visualizing the Valsalva Sinuses

LCC

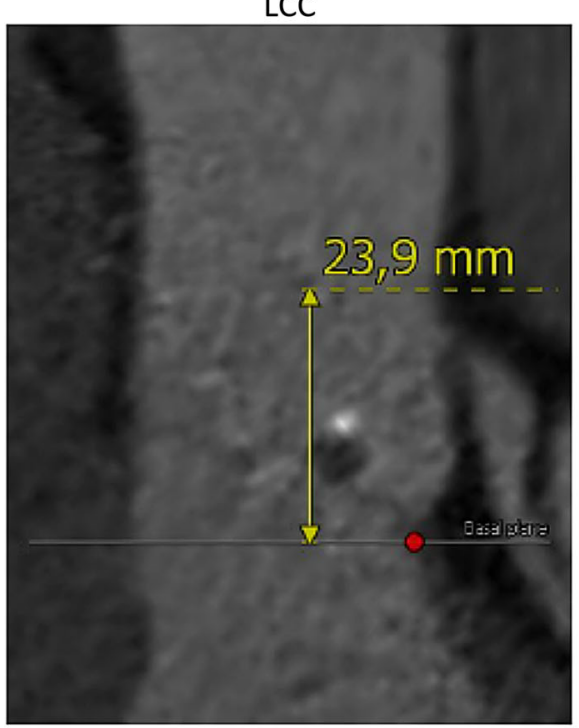

RCC

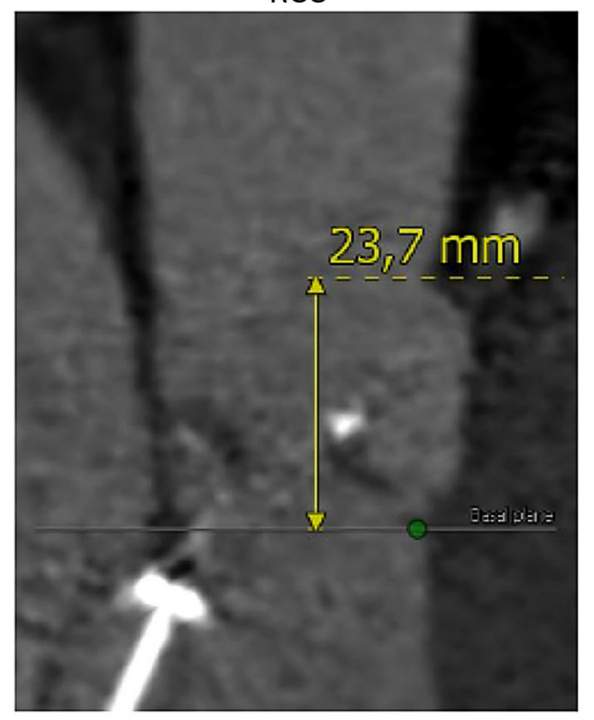

NCC

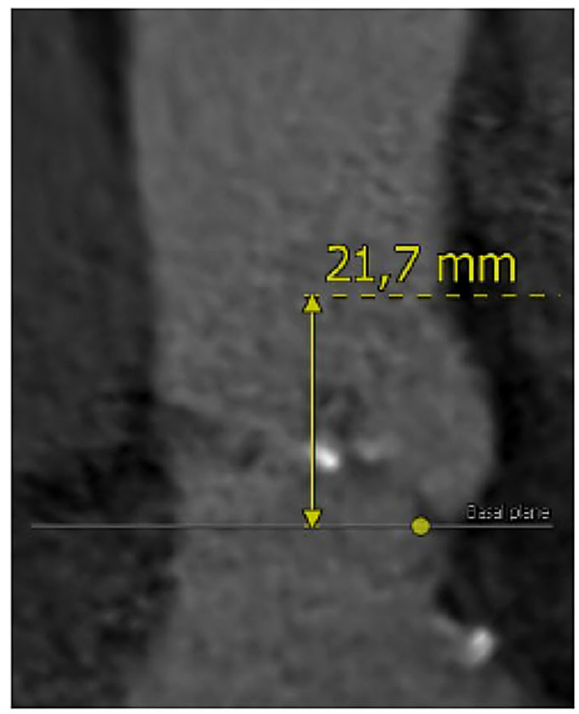


Fig. 5. 3D reconstruction of mitral valve and TAVI implantation zone

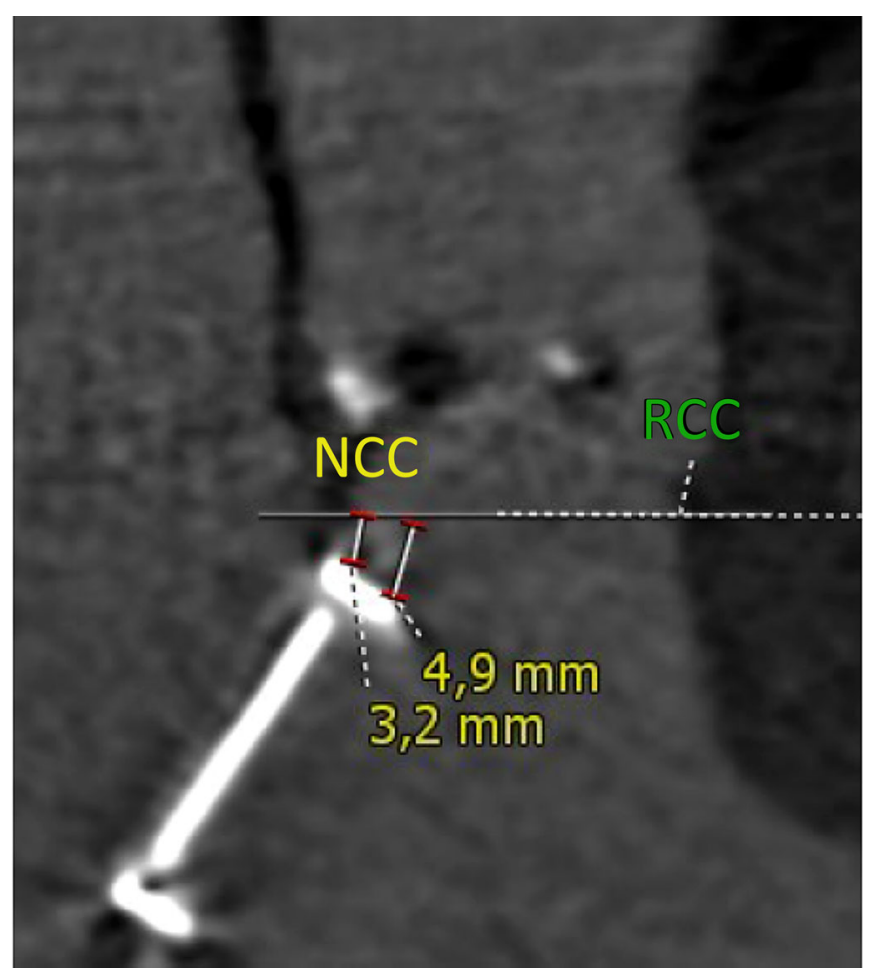
found.

- No significant stenosis of the carotid vessels was

- The CT angiography of the iliofemoral segment did not reveal any significant narrowing of the arterial diameter or any vulnerable atherosclerotic plaques (Fig. 6 and 7).

Fig. 6. 3D reconstruction of possible right side femoral access.

\section{Femoral Access - Right}
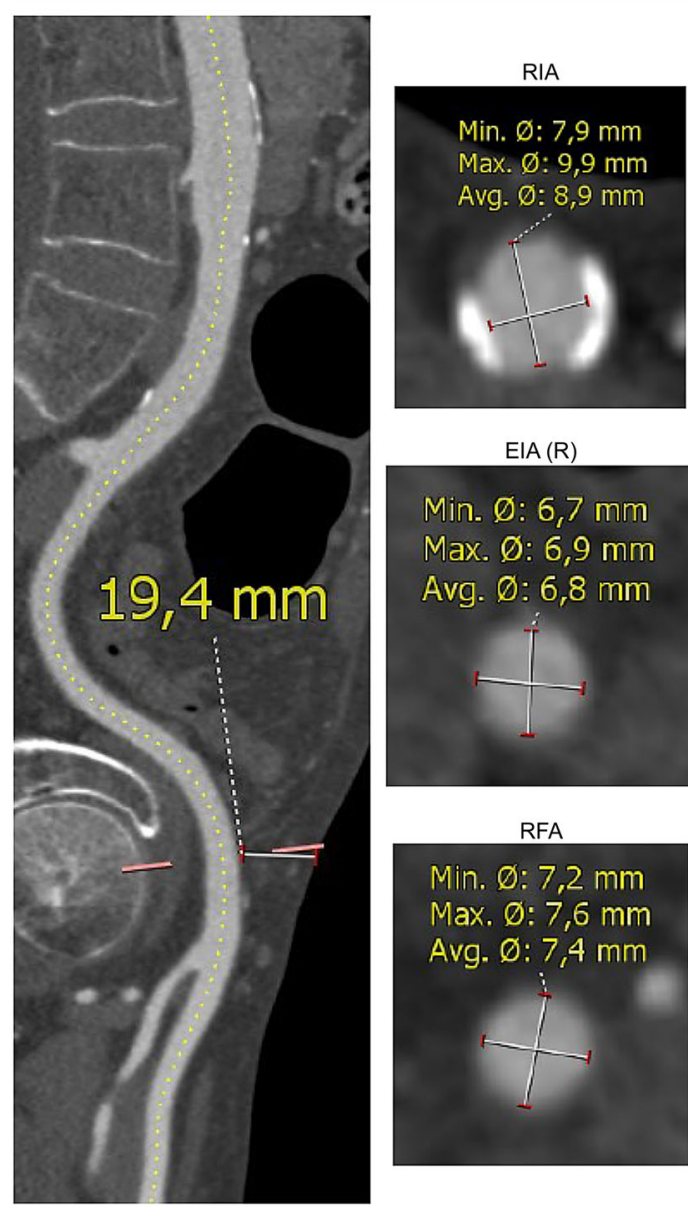

$\operatorname{EIA}(R)$

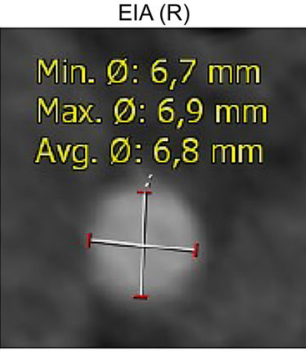

RFA

Min. Ø: 7,2 mm

Max. $\emptyset: 7,6 \mathrm{~mm}$

Avg. $\varnothing: 7,4 \mathrm{~mm}$
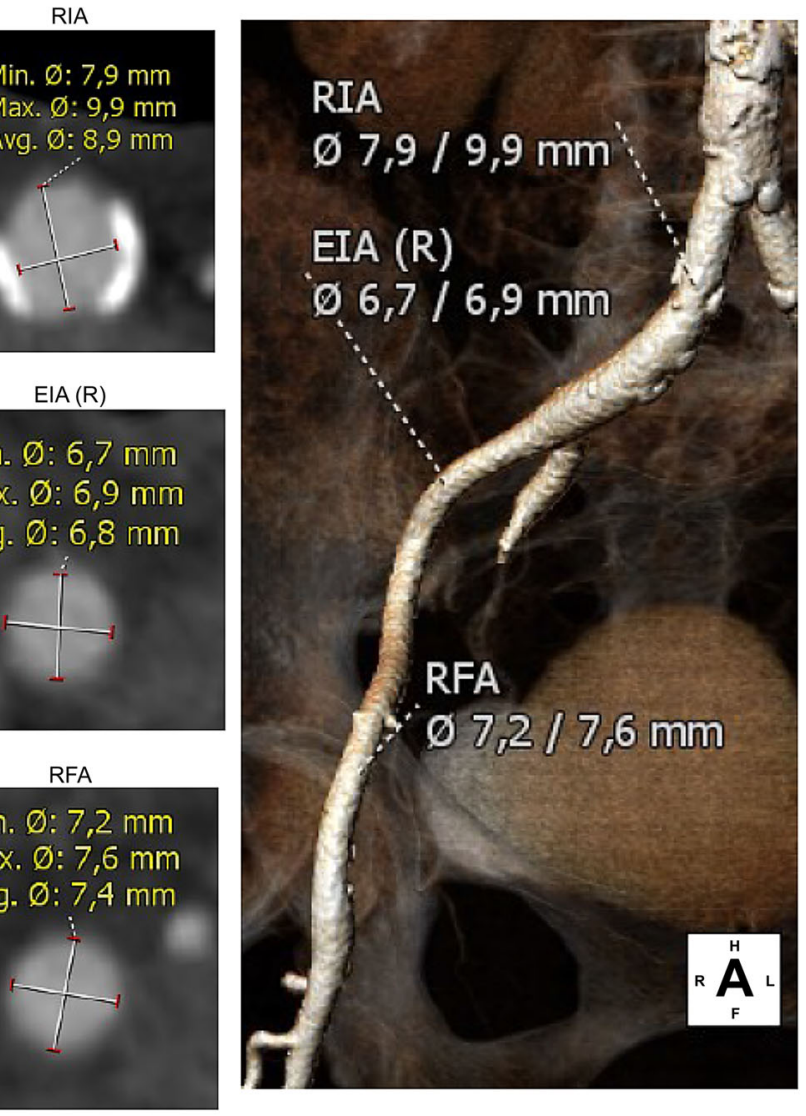
Fig. 7. 3D reconstruction of possible left side femoral access.

\section{Femoral Access - Left}
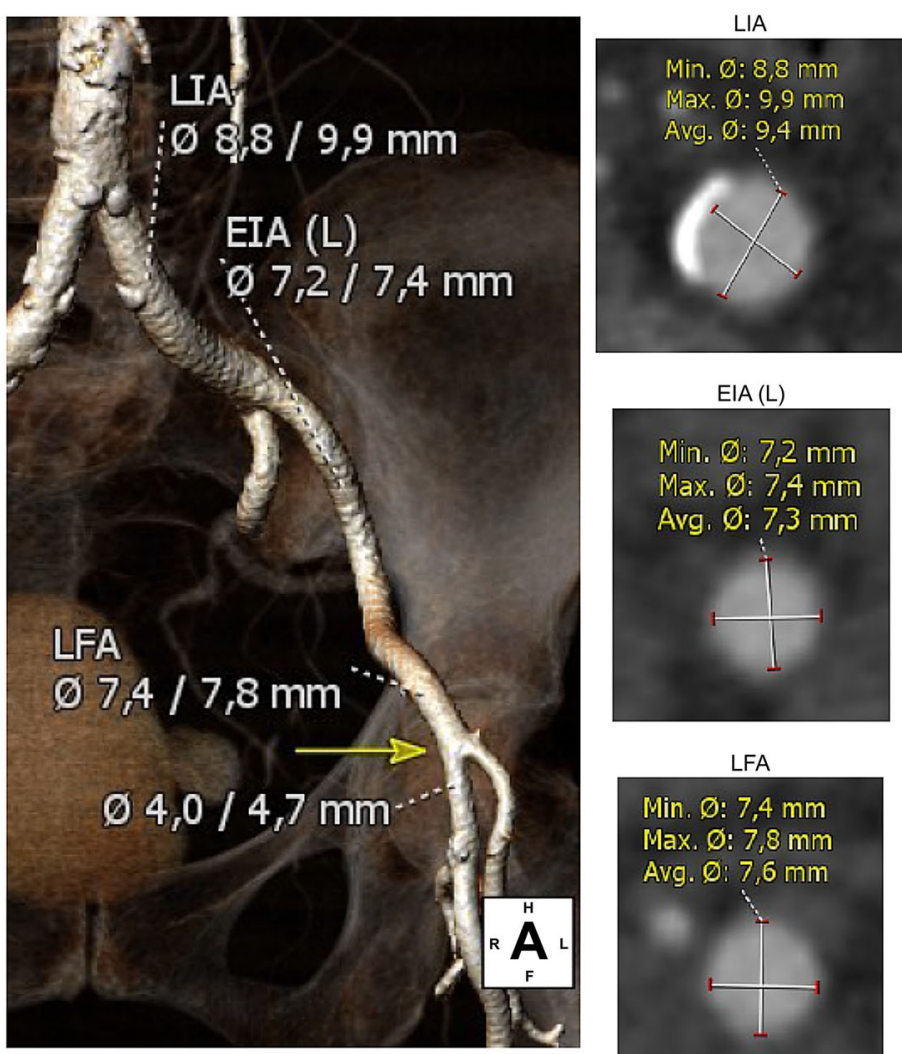

EIA (L)

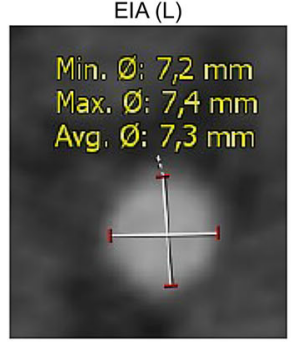

LFA
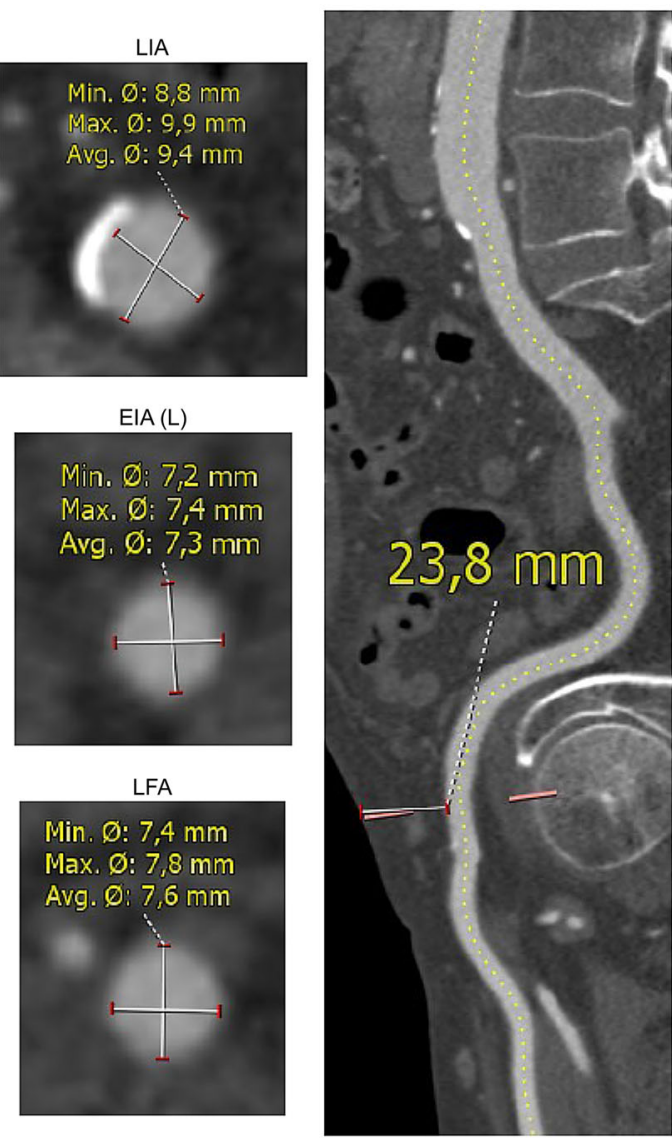

The results of the imaging methods showed that the patient meets the anatomical requirements for this procedure and after she gave her consent she received a date for hospitalization and TAVI implantation.

The transcutaneous implantation of aortic valve prosthesis was performed under general intubation anesthesia and went through the standard procedure steps, taking into consideration the limited space for the valve (Fig. 8, 9 and 10).

Fig. 8. Aortic root and mitral valve before implanting the TAVI

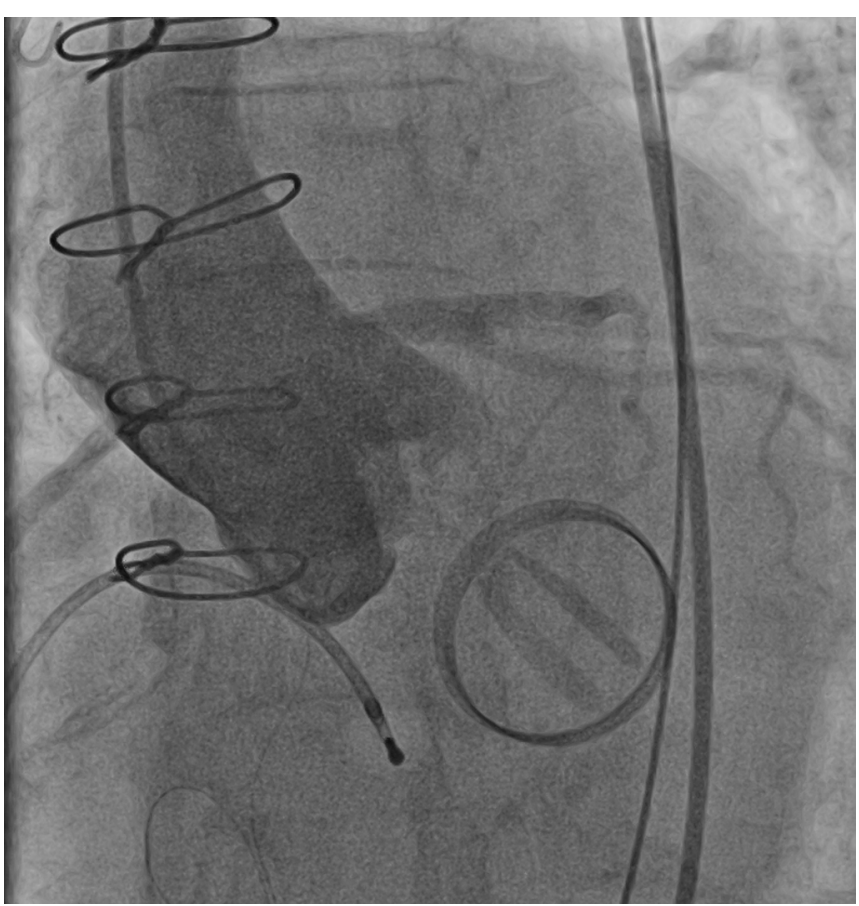


Fig. 9. Unexpanded valve in implantation position

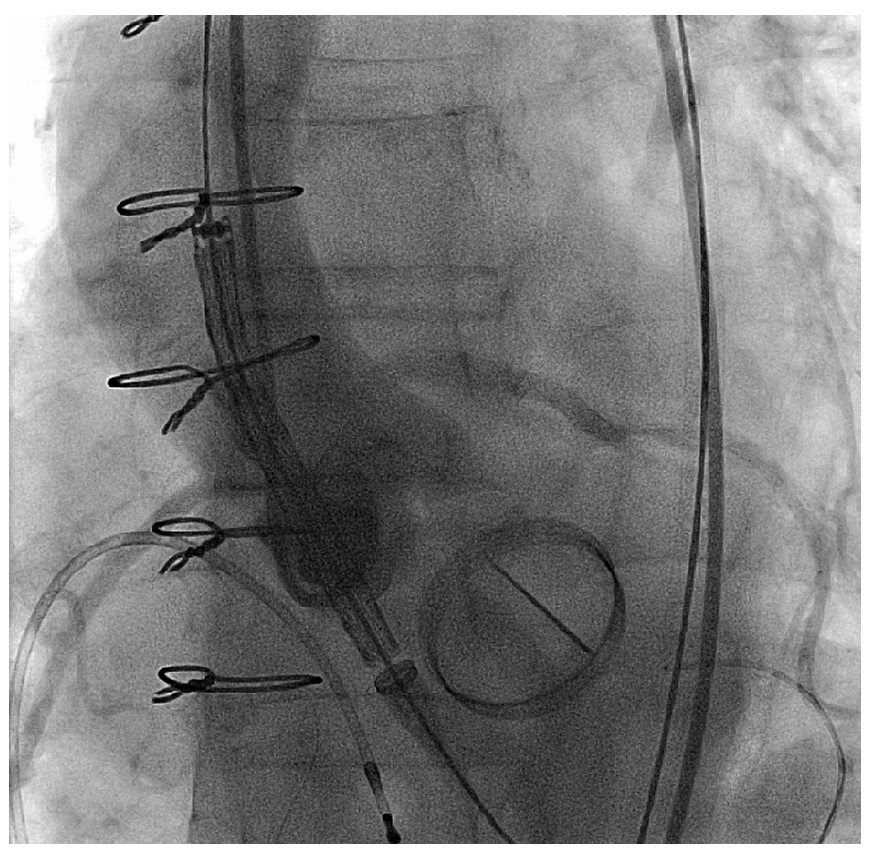

Fig. 10. Aortography after the implantation in order to reveal any paravalvular leak

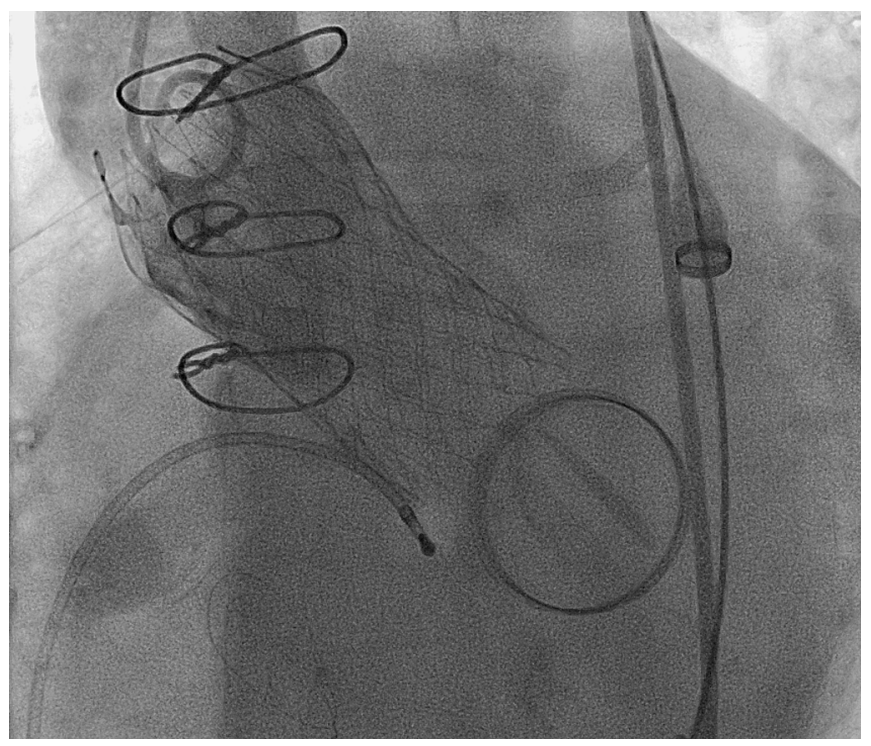

The patient was extubated three hours after the procedure. No complications were observed during the implantation and the 24 hours following it. Implantation of a permanent pacemaker was not needed since no conduction disturbances were detected. Dual antiplatelet therapy for 6 months and then monotherapy with Aspirin for life was prescribed as according to the guidelines.

The echocardiography that was performed three days after the implantation revealed a normal function of both artificial valves: first degree mitral and aortic regurgitation, $22 \mathrm{mmHg}$ peak gradient through the aortic prosthesis which is within the norm.

The echocardiography at 1 month follow-up showed minimal paravalvular leak 0 -I degree.

\section{DISCUSSION}

Performing a Computer Tomography before the procedure is of crucial importance for the safety of the procedure. Careful measurement of the distance between the aortic and mitral anulus (the target site of the expansion of the valve in LVOT next to the base of the mitral valve) is necessary for a sucessful procedure. Another useful imaging method is transesophageal echocardiography.

In order to prevent possible periprocedural complications the following precautions should be taken:

1. The aorto-mitral zone should be carefully explored before the procedure using CT scan and TEE in order to assess the mitral prosthesis, the size and condition of the aortic valve (including the amount of calcium, the size of the aortic annulus, the valsalva sinuses and the ascending aorta) and also the distance between the two valves.

2. During the baloon predilatation, events like dislocation and impression of the balloon a should be noted and analysed.

3. The angiographic view that shows best the distance between the two valves should be selected.

4. The expansion of the valve should be done slower so a possible dislocation can be noticed and corrected.

5. Intraprocedural TEE should be used to guide the positioning and proper expansion of the valve and also to show any paravalvular leaks that might occur.

One of the most important preparation steps is the analysis of the mitral valve. Since the profile of the artificial mitral valve determines how the TAVI procedure is performed, the size of the MVP and the height of its base are of crucial importance. According to the available literature data, the transapical approach is preferred over the transfemoral one. There is still no consensus available regarding the distance which should be kept between the two prostheses in order to avoid all possible complications. Most authors consider a $3 \mathrm{~mm}$ distance between the lower border of the lowest strut of the aortic valve to the highest edge of the mitral valve be enough when a transapical approach is chosen. A possible reasonable distance in transfemoral approach is $7 \mathrm{~mm}$. There are multiple articles regarding the transfemoral approach in such a procedure and its specific challenges and implantation tactics. The main factor limiting the use of transfemoral approach up until now was the excessive movement of the artificial valve and the impaired movement of the delivery system. This stopped being a consideration after the modernization of the delivery system. One of the most common postprocedural complications is the impaired blood flow through the mitral valve, caused by the artificial aortic valve. The TEE control during the procedure and follow up show normalisation of the hemodynamics of both valves $[7,8,9]$. 


\section{CONCLUSION:}

Transcatheter implantation of an aortic valve prosthesis in the presence of a mitral prosthesis can be a reliable and safe procedure with a smooth post-implantation period. Methodical planning and discussion by a multidisciplinary team are of the essence. Considering the experience of many authors in world literature, patients with aortic stenosis and mitral prosthesis should be strongly advised to carry out such a procedure. Last but not least, we must mention the importance of the skills and experience of the operator for the smooth running of the procedure.

\section{REFERENCES:}

1. Cribier A, Eltchaninoff $\mathrm{H}$, Bash A, Borenstein N, Tron C, Bauer F, et al. Percutaneous transcatheter implantation of an aortic valve prosthesis for calcific aortic stenosis: first human case description. Circulation. 2002 Dec;106(24):3006-8. [PubMed] [CrossRef]

2. Holmes DR Jr, MacK MJ, Kaul S, Agnihotri A, Alexander KP, Bailey SR, et al. 2012 ACCF/AATS/SCAI/STS expert consensus document on transcatheter aortic valve replacement. $J$ Am Coll Cardiol. 2012 Mar 27;59 (13):1200-1254. [PubMed] [CrossRef]

3. Leon MB, Smith CR, Mack M, Miller DC, Moses JW, Svensson LG, et al. Transcatheter aortic-valve implantation for aortic stenosis in patients who cannot undergo surgery. $N$ Engl J Med. 2010 Oct 21;363(17):1597-

\section{7. [PubMed] [CrossRef]}

4. Chao VT, Chiam PT, Tan SY. Transcatheter aortic valve implantation with preexisting mechanical mitral prosthesis - use of CT angiography. J Invasive Cardiol. $2010 \mathrm{Jul} ; 22(7)$ : 339-40. [PubMed]

5. Soon JL, Ye J, Lichtenstein SV, Wood D, Webb JG, Cheung A. Transapical transcatheter aortic valve implantation in the presence of a mitral prosthesis. J Am Coll Cardiol. 2011 Aug 9;58(7):715-21. [PubMed] [CrossRef]

6. O'Sullivan KE, Hurley ET, Sugrue D, Hurley JP. Patients with a mechanical mitral valve are potential candidates for TAVI. $\mathrm{Br} J$ Cardiol. 2015 Apr;22:(2). [CrossRef]

7. Garcia E, Albarran A, HerediaMantrana J, Guerrero-Pinedo F,
Rodriguez J, Hernandez-Antolin R, et al. [Transcatheter aortic valve implantation in patients with a mechanical mitral valve]. [in Spanish] Rev Esp Cardiol. 2011 Nov;64(11):1052-5. [PubMed] [CrossRef]

8. Kahlert $\mathrm{P}$, Eggebrecht $\mathrm{H}$, Thielmann M, Wendt D, Jakob HG, Sack S, et al. Transfemoral aortic valve implantation in a patient with prior mechanical mitral valve replacement. Herz. 2009 Dec;34(8):645-7. [PubMed] [CrossRef]

9. Bruschi G, De Marco F, Oreglia J, Colombo P, Fratto P, Lullo F, et al. Percutaneous implantation of Core Valve aortic prostheses in patients with a mechanical mitral valve. Ann Thorac Surg. 2009 Nov;88(5):e50-2. [PubMed] [CrossRef]

Please cite this article as: Valkov V, Kalchev D, Kostadinov A, Kashlov Y, Kanazirev B. Transcatheter aortic valve implantation in a patient with prosthetic mitral valve- clinical case. J of IMAB. 2018 Apr-Jun;24(2):2007-2013. DOI: https://doi.org/10.5272/jimab.2018242.2007

Received: 25/03/2018; Published online: 04/06/2018

Address for correspondence:

Veselin Valkov,

First Clinic of Cardiology, Department of Internal Medicine, UMHAT St.Marina, Varna;

1, Hr. Smirnensky blvd., Varna, Bulgaria.

Mob: +359889232505

E-mail: vd.valkoff@abv.bg

https://www.journal-imab-bg.org 